\title{
A FEMALE CHILD WITH RECURRENT PNEUMONIA AND WEBBING OF NECK
}

Senthil Kumar Palaniappan, Thiyagarajan Srinivasan.

Department of Pediatrics, Masonic Medical Centre for Children, Coimbatore, Tamilnadu, India.

\section{KEYWORDS}

Sex Chromosome, Aneuploidy, Trisomy $\mathrm{X}$
ARTICLE HISTORY

Received 6 March 2021

Accepted 26 March 2021

\section{Clinical Problem:}

A 4 years old female child was admitted with hurried breathing for one day, fever with cough and cold for three days. She was admitted thrice previously for pneumonia elsewhere. She underwent closure of patent ductus arteriosus (PDA) at 1 year 6 months of age. She was born by lower segment cesarean section to non-consanguineous parents and had birth weight of $3 \mathrm{~kg}$. Developmental history was normal. She received immunization as per universal immunization programme. On examination, she was sick looking with respiratory distress. Her heart rate was 152/ min, respiratory rate was $62 / \mathrm{min}$, oxygen saturation was $95 \%$ at room air. She had left convergent squint with webbing of neck (Figure 1). She had intercostal and subcostal retractions with bilateral crepitations on auscultation. Chest X-ray showed bilateral patchy infiltrates suggesting bronchopneumonia. Complete blood counts showed total white blood cell (WBC) count of 10940 cells/cumm with polymorphs $77 \%$ and lymphocytes $23 \%$. C-reactive protein was 68.5 mgs/L. PCR for H1N1 influenza virus by throat swab was negative. Sputum was negative for acid fast bacilli (AFB) on smear and GeneXpert for mycobacterium tuberculosis (MTB) was also negative. She was treated with nasal oxygen, intravenous (IV) antibiotics (ceftriaxone, vancomycin), oral azithromycin and IV fluids to which she responded. Her immunoglobulin profile (IgG: $936 \mathrm{mg} / \mathrm{dl}$, IgE: $67 \mathrm{IU} / \mathrm{ml}$, IgM: $123 \mathrm{mg} / \mathrm{dl}$, IgA: $43 \mathrm{mg} / \mathrm{dl}$ ) and nitro blue tetrazolium (NBT) assay (NBT positive cells: 96\%) were normal. Karyotype is depicted in figure 2 .

What is the diagnosis?

\section{Discussion:}

Karyotyping showed three $X$ chromosomes confirming Trisomy $X$ also known as Triple $X$ syndrome. Trisomy $X(47, X X X)$ is characterized by the presence of an additional $X$ chromosome in the affected females compared to the $46, X X$ in normal females. ${ }^{1}$ Even though newborn screening program showed the

Address for Correspondance: Dr. Senthil Kumar Palaniappan, Consultant Pediatrician, Masonic Medical Centre for Children, Coimbatore-641018, Tamilnadu, India.

Email: drvpsk@rediffmail.com

(C2021 Pediatric Oncall
Figure 1. Webbing of neck

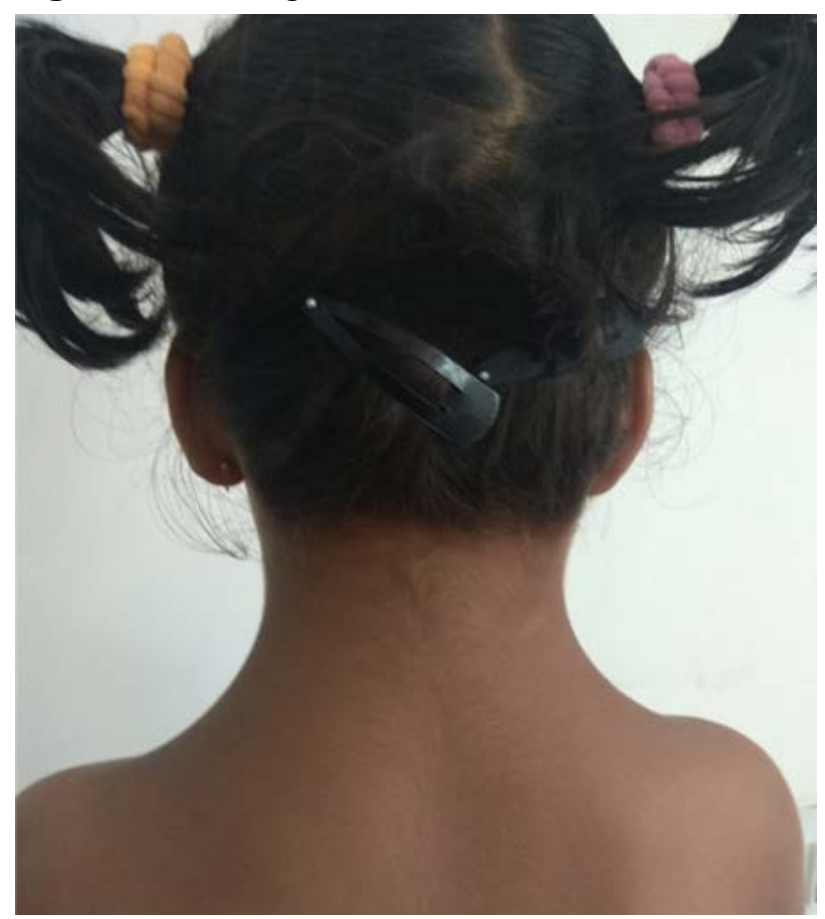

Figure 2. Karyotype of the patient

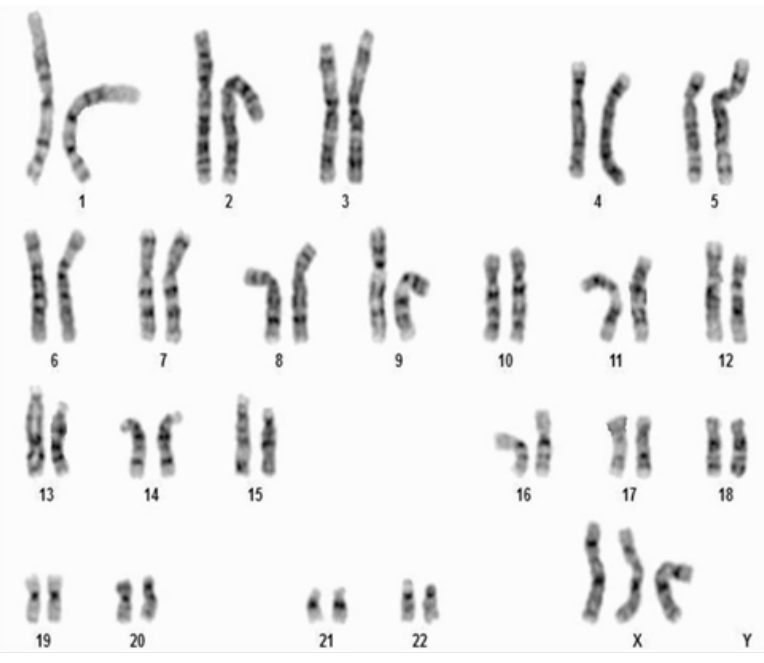

incidence is 1 in 1000 normal females, majority of the individuals with Triple $X$ syndrome may go unnoticed due to very subtle phenotypic abnormalities, socially 
acceptable intelligence, and normal sexual development and fertility. ${ }^{2}$ In these patients, anthropometry at birth is usually appropriate for gestational age. These females are usually normal in height or tall. ${ }^{3,4}$ In fact tall females with infertility should undergo karyotyping to rule out Triple $X$ syndrome. Microcephaly is rare. ${ }^{4}$ Children with trisomy $X$ may have early developmental delays involving motor and/or speech and language domain. They may have delayed walking, hypotonia, seizure disorder, joint hyperextensibility and poor coordination in early childhood. ${ }^{4}$ Even though intellectual abilities vary greatly, many children have normal IQ scores. Attention-deficit hyperactivity disorder and language disorders particularly expressive language are seen in some children. ${ }^{4}$ Major dysmorphological features are not frequently seen in $47, X X X$. But minor physical findings are seen in some patients including hypertelorism, up slanting palpebral fissures, epicanthal folds, pectus excavatum, clinodactyly, overlapping digits and pes planus. ${ }^{4}$ Most common abnormalities are genitourinary which includes unilateral renal dysplasia, multicystic renal dysplasia, bladder exstrophy and ovarian malformations. Congenital heart defects include atrial and ventricular septal defects, pulmonary stenosis, and coarctation of aorta. ${ }^{4}$ Even though immunodeficiency is not reported, recurrent respiratory infections are reported as the most common reason for hospitalization among other medical conditions in Trisomy X. ${ }^{5}$ Our patient had recurrent respiratory infections. Increased rates of autoimmune disorders such as autoimmune thyroiditis have also been reported. ${ }^{4}$ Onset of puberty and sexual development are usually normal in trisomy $X$. However few patients have ovarian or uterine dysgenesis or premature ovarian failure. ${ }^{4}$ Fertility is normal unless complicated by a genitourinary malformation or premature ovarian failure. ${ }^{4,6}$ Trisomy $X$ results from a nondisjunction in which the $X$ chromosomes fail to separate during gametogenesis or after fertilization (post zygotic nondisjunction). ${ }^{4}$ This error results in cells that contain three $X$ chromosomes instead of two $X$ chromosomes present in normal females. Maternal nondisjunction is more common than paternal nondisjunction which increases with increasing maternal age. ${ }^{4}$ Mosaicism occurs in approximately $10 \%$ of cases due to mitotic errors occurring after fertilization. ${ }^{1,4}$ Karyotyping is the most standard test used to get the diagnosis. Prenatal diagnosis by amniocentesis or chorionic villus sampling is also possible. After birth, confirmatory testing by karyotype or florescence in situ hybridization (FISH) is recommended to confirm the diagnosis and to evaluate for mosaicism. Since nondisjunction is a random event, risk of recurrence for Trisomy $X$ in future pregnancies is less than $1 \%$. But increased maternal age is a risk factor for any type of aneuploidy. ${ }^{4}$ Management approach is mainly multidisciplinary. Periodic developmental assessments should be done to evaluate cognitive, language, motor, and socialemotional development with follow-up intervention. Cardiac, endocrine and neurological evaluation, ultrasound abdomen, thyroid profile should be done in all cases which should be followed by appropriate interventions if necessary. The prognosis of trisomy $X$ is variable and depends on the severity of manifestations. ${ }^{7}$

\section{Conclusion:}

Karyotyping should be considered in any child with dysmorphic features (even subtle) particularly associated with congenital heart disease.

\section{Compliance with ethical standards}

Funding: None

Conflict of Interest: None

\section{References:}

1. Skuse D, Printzlau F, Wolstencroft J. Sex chromosome aneuploidies. Handb Clin Neurol. 2018;147:355-376.

2. Robinson A, Bender BG, Borelli JB, Puck MH, Salbenblatt JA, Winter JS. Sex chromosomal aneuploidy: prospective and longitudinal studies. Birth Defects Orig Artic Ser. $1986 ; 22: 23-71$

3. Ottesen AM, Aksglaede L, Garn I, Tartaglia N, Tassone F, $\mathrm{Gravholt} \mathrm{CH}$, et al. Increased number of sex chromosomes affects height in a nonlinear fashion: a study of 305 patients with sex chromosome aneuploidy. Am J Med Genet A. $2010 ; 152 \mathrm{~A}: 1206-1212$.

4. Tartaglia NR, Howell $S$, Sutherland A, Wilson R, Wilson L. A review of trisomy X $(47, \mathrm{XXX})$. Orphanet J Rare Dis. 2010;5:8.

5. Wigby K, D'Epagnier C, Howell S, Reicks A, Wilson R, Cordeiro L, Tartaglia N. Expanding the phenotype of Triple $X$ syndrome: A comparison of prenatal versus postnatal diagnosis. Am J Med Genet A. 2016;170:2870-2881

6. Stagi S, di Tommaso M, Scalini P, Lapi E, Losi S, Bencini $E$, et al. Triple $X$ syndrome and puberty: focus on the hypothalamus-hypophysis-gonad axis. Fertil Steril. 2016;105:1547-1553.

7. Otter M, Schrander-Stumpel CT, Curfs LM. Triple $X$ syndrome: a review of the literature. Eur J Hum Genet. 2010;18:265-271. 